\title{
Pathology reports solve "new bowel disease" riddle
}

\author{
Unpublished data from the research that claimed links between MMR vaccine, autism, and \\ enterocolitis reveal no enterocolitis. Brian Deer investigates
}

\section{Brian Deer journalist}

London, UK

In a surprising new twist to the Andrew Wakefield MMR scandal, the $B M J$ has obtained a bundle of pathology reports that further unmask how the appearance of links between the vaccine, autism, and inflammatory bowel disease was created at a London medical school.

The unsigned and undated reports ${ }^{1}$ are analyses of intestinal biopsies from children enrolled in Wakefield's now infamous study published in the Lancet in February $1998 .{ }^{2}$ The paper triggered a collapse in UK immunisation rates and led to worldwide controversy over the vaccine's safety. In May last year, Wakefield was struck off the UK medical register over a raft of misconduct charges, including four counts of dishonesty over the research. ${ }^{3}$ And in January 2011, my BMJ series "Secrets of the MMR scare" ${ }^{4}$ documented what the journal's editors called an "elaborate fraud" behind the alarm. ${ }^{5}$

Those findings focused on the detection of widespread falsification over patient selection criteria, clinical histories, and neuropsychiatric diagnoses. All were essential to Wakefield's media grabbing allegation that MMR was the apparent cause of regressive autism, purportedly within days of vaccination.

Now, the new material opens a window into a second side of the project: an attempt by the former gastrointestinal surgeon to prove that the combined measles, mumps, and rubella vaccine caused a "new variant" inflammatory bowel disease.

Between 1988 and 2001, Wakefield was an academic researcher at the Royal Free medical school in Hampstead, north London, from which his five page paper was published. "Researchers at the Royal Free Hospital School of Medicine may have discovered a new syndrome in children involving a new inflammatory bowel disease and autism," the school announced to promote the paper, which the Lancet retracted last year.

\section{"Overwhelmingly normal"}

But the data-passed to us by David Lewis, a self employed American environmental microbiologist working with Wakefield—tell a different story, kept hidden for nearly 14 years. "I'm astonished, really," said Paola Domizio, a consultant histopathologist and professor of pathology education at Queen Mary's College, London, after we showed her the material.

"Quite extraordinary," commented Ingvar Bjarnason, professor of gastroenterology at King's College London.

The data take the form of histology scoring sheets for 62 intestinal specimens taken from 11 of 12 children whose cases were reported in the Lancet. The sheets were completed in 1997 or early 1998 by Amar Dhillon, now professor of histopathology at the Royal Free medical school, today part of University College London.

Dhillon-to whom we have supplied copies of his reports-was among 12 staff, including another consultant pathologist and three consultant gastroenterologists, who signed up to Wakefield's claims in the paper of a putative "new syndrome" of vaccine associated bowel and brain damage.

"We investigated a consecutive series of children with chronic enterocolitis and regressive developmental disorder," said the 4000 word "early report."

"We describe a pattern of colitis and ileal-lymphoid nodular hyperplasia in children with developmental disorders . . the uniformity of the intestinal pathological changes and the fact that previous studies have found intestinal dysfunction in children with autistic-spectrum disorders, suggests that the connection is real and reflects a unique disease process." In a further paper, retracted in May 2010 by the American Journal of Gastroenterology, Wakefield dubbed this alleged disease "autistic enterocolitis." And, in a secret report to the government's Legal Aid Board, that unlocked $£ 18 \mathrm{~m}(€ 21 \mathrm{~m}$; $\$ 28 \mathrm{~m}$ ) of taxpayers' money for the attack he led against MMR, he said: "the pathology appears to represent a novel inflammatory bowel disease that is associated with autism.", But Dhillon's reports produced results that pathologists, gastroenterologists, and a gastrointestinal immunologist to whom we have shown them say are overwhelmingly normal and might be found in almost anybody's gut. 


\begin{abstract}
"Most of this stuff is so close to normal that you've really got to question whether there is really anything there," said Henry Appelman, professor of surgical pathology at the University of Michigan and a specialist in gastrointestinal disease. "These are the kind of things that we in our practise here would ignore completely."
\end{abstract}

Dhillon's gradings - from slides that are said to have been lostare marked on single sided A4 forms that he devised himself ${ }^{8}$ and are not known to be used elsewhere. They itemise four criteria to evaluate inflammation against a four step severity score.

In contrast with the paper's claims about enterocolitis, of 248 data points generated in Dhillon's scores, 186 are reported "normal" against his own criteria, including 35 of 36 from nine ileal specimens (figure $\Downarrow$ ). In two of the 11 children, endoscopy could not reach the small intestine because of gross faecal loading.

Ceaselessly challenged by antigens, normal bowel mucosa is sometimes described as being in a state of "controlled inflammation." But Dhillon reported none of the children's specimens with "destructive epithelial damage" - the hallmark of colitis. ${ }^{10}$ Nor did he note any superficial erosions, aphthoid ulcers, frank ulceration, crypt abscesses, or pus.

Most damaging to Wakefield's claim of "autistic enterocolitis"- submitted by lawyers as the key construct in now failed multiparty lawsuits over MMR in Britain ${ }^{11}$ and the United States ${ }^{12}$-Dhillon did not find enterocolitis in any child. "It is definitely not correct that the children had enterocolitis," said Karel Geboes, professor emeritus of pathology at the gastrointestinal pathology unit of the Catholic University of Leuven, Belgium. "It is also not correct to state that the intestinal pathological changes were uniform."

\section{Objections were withdrawn}

Last year I revealed in the $B M J$ that double signed, printed reports from the Royal Free Hospital's pathology service, led by consultant histopathologist Susan Davies, had documented healthy biopsy specimens that were later reported in the Lancet as diseased..$^{13} \mathrm{~A}$ draft of the paper, circulated months before publication, did not include Davies among its authors.

But a General Medical Council (GMC) panel considering the Wakefield case heard from Davies, now at Addenbrooke's Hospital, Cambridge, that after challenging claims of "colitis" in the draft, she withdrew her objections in deference to a "research review" by Dhillon. ${ }^{14}$ In light of that, some of the authors met and agreed that the paper, already intended for submission to the high impact journal, was accurate and, despite the omission of Davies's normal findings, she was credited with authorship.

"It should be appreciated that the term 'colitis' covers a range of changes," she said last year, defending her decision, "from minimal, self-limiting and non-specific, to extensive, severe and characteristic; such [that] it is difficult to select a point from within a spectrum for a single definition." 15

But it now emerges that, although expressed as scores rather than narratives, Dhillon's findings were largely consistent with Davies's. "Everyone thinks I am crazy even asking them," said King's gastroenterologist Bjarnason, after discussing the scorings with other specialists. "All but one of the children is normal in their eyes. There is no enteritis and no colitis, simple as that."
Of the 62 data points not reported by Dhillon as "normal," 39 are from observations of what the pathologist called a "slight increase in lamina propria mononuclear cells," while another six show "occasional lamina propria polymorphs."

But these findings are well recognised as not being diagnostic of colitis. ${ }^{16-21}$ "It should be noted that the diagnosis of colitis requires evidence of injury to the epithelium, and not simply a mild increase in the amount of chronic inflammatory infiltrate within the lamina propria," says, for example, Elizabeth Montgomery, a pathologist at Johns Hopkins University, Baltimore, in a standard textbook. ${ }^{22}$

Bifid glands—generally considered unremarkable—are noted by Dhillon in five patients, and for only two did his observations of cell numbers find more than what he calls "slight" increases or "occasional" inflammatory cells. In one child, a rectal biopsy specimen was reported to show a "moderate" increase in lymphocytes and plasma cells, while in another moderate increases were noted in the transverse, descending, and sigmoid colon, with a "marked" increase in lymphoid aggregate (where lymphocytes self evidently proliferate) in the child's ascending colon.

No cell counts or clinical diagnoses appear on the forms, and neither Crohn's disease nor ulcerative colitis was even considered "possible" by Dhillon. But, according to the Lancet paper, 11 of the 12 patients were reported histologically with chronic "non-specific colitis"-in five of whom it was also said to be acute.

Nowhere does Dhillon use this expression, although he does have a tick box "non-specific." And it is this, Wakefield says, that gave him authority to report that all but one of the 12 children had colitis.

"A comparison of the Lancet article with the records Wakefield used to write it proves that Wakefield faithfully and accurately reproduced the records he was given," argues Lewis, who began looking into Wakefield's case after attending an anti-vaccine conference in Jamaica last January.

But experts we consulted say this interpretation is wrong. The grading sheets were also used for small intestinal biopsies, which could not show colitis, and reports compiled by Andrew Anthony, a trainee pathologist assisting Dhillon, used a different form that included the term "non-specific changes," although he did not tick that option for any of the biopsies.

'I suspect when he ticked 'non-specific,' he wasn't trying to say 'non-specific colitis,'” says Domizio, of Queen Mary's, regarding Dhillon's scorings. "He was trying to say 'changes of uncertain significance."”

The case of the first child in the series-a 3 year old boy-illustrates the strange situation. Both Davies and Dhillon found mild caecal inflammation, with no abnormality or changes in other biopsies. But the Lancet paper expanded the pathology to "Acute caecal cryptitis and chronic non-specific colitis."

\section{Key findings omitted}

Longstanding concerns over how Wakefield reached his conclusions escalated in January of last year with the first findings from the GMC panel, which ruled that key elements of the Lancet paper were intentionally dishonest. And in the same month, the mystery over his results deepened when an expert panel published a consensus statement in Pediatrics stating that no gastrointestinal disturbance specific to autism had been established. "Other study-design limitations in these reports included flawed control groups, lack of validated and 
standardized definitions, and speculative interpretation of results," the authors said with regard to Wakefield's papers." 23 He did not act alone, however, and the new information has raised questions not only for pathologists. Clinicians, led by John Walker-Smith, the Royal Free's professor of paediatric gastroenterology, who was struck off with Wakefield last year and is appealing this decision, initially screened the children using a panel of blood tests for inflammation that could have helped avoid unnecessary colonoscopies. ${ }^{24}$

But when these tests gave normal results, he set them aside, later allowing their omission from the Lancet. And despite these findings, the study's developmentally challenged patients, aged between 3 and 9, were brought to the hospital for ileocolonoscopy. Davies's team's biopsy results were then also found to be largely normal, but these too were set aside and not disclosed.

Finally, came Dhillon whose humdrum findings were announced as a new disease.

"The parents were right," Wakefield declared in a letter to the Lancet, three weeks after the paper, referring to a group I later revealed to be handpicked families seeking compensation. "They have helped us to identify a new inflammatory bowel disease that seems to be associated with their child's developmental disorder." 25

At the time, the "syndrome" was proposed to have another bowel feature: lymphoid nodular hyperplasia. But, again, although this was identified in the paper's findings, discussion, tables, and title, there was nothing in the references, and the paper did not mention that it had long been viewed by gastroenterologists as a common "benign" or "normal" sign in children. ${ }^{26-29}$

"I think they were probably scoring the lymphoid follicles as inflammation," says Domizio. "They were scoring what should have been ignored."

That something like this may have been going on at the Royal Free seemed to be supported during the Wakefield GMC case. Walker-Smith has previously declined to comment to the $B M J$, citing his appeal, but he told the panel that when he met Dhillon, "it was obvious to him that the lymphoid nodular hyperplasia in the colon itself, that finding per se, was in his view a marker of colitis."

No less controversial, the authors omitted from the paper the children's principal gastroenterological problem. "Almost all" had "severe" constipation. ${ }^{30}$ The GMC panel heard, for example, that after bowel preparation by nasogastric tube, the first patient, who had mild caecal cryptitis, endured two attempted ileocolonoscopies that failed because of faeces in the caecum, with "scope trauma" noted on the second.

This omission of constipation was no small matter. It went to the heart of how the paper would be read. Specialists told me that both mild inflammation and prominent lymphoid follicles may be expected to be associated with this sign.

"The increase of colonic lymphoid aggregates found in severely constipated patients may represent a protective mucosal mechanism toward the chronic fecal stasis," suggests a team of Italian and Swiss researchers, for example, in a study of adults. ${ }^{31}$

But such prosaic observations would not have helped the lawsuits-for which Wakefield was hired before any child was referred, and which in the UK paid him more than $£ 400000$. Five other Royal Free doctors-Davies and Dhillon were not among them—shared more than $£ 100000$ to back him.

According to court documents, they were trying to prove a theory of Wakefield's that measles virus from MMR persisted in the gut and caused the bowel to become inflamed and "leaky." This purportedly "led to the escape of opioid peptides" into the bloodstream, which travelled to the brain and caused autism. ${ }^{32}$

"They had to create a new disease, and when Susan Davies got normal results they were in trouble," argues Tom MacDonald, a gastrointestinal immunologist and dean of research at Barts and the London school of medicine. He has published on Wakefield's findings with Domizio, ${ }^{33}$ and both have consulted for vaccine manufacturers, inspecting some of the biopsy slides. "If there wasn't IBD [inflammatory bowel disease], then Wakefield's whole theory collapsed, and with it the litigation which was paying him."

Dhillon told me that he had not kept copies of his grading sheets and had not seen the originals since giving them to Wakefield. "Brian, after I hand over proformas to somebody, what am I going to do with them?" he said. But he added that, since the $B M J$ articles in January, University College London has ruled that all queries must be directed to senior managers.

"I did not write the histology section of the paper," he said in a statement to GMC lawyers in July 2006. "I do not know if any other histopathologists undertook the same review exercise with the slides as me, and I did not see their observations."

Wakefield, meanwhile, now self employed in Austin, Texas, says he had nothing to do with the findings. Although the paper stated that he "assessed" the biopsy specimens with Dhillon and the trainee Anthony, Wakefield has since claimed this is wrong.

"Dr Dhillon's diagnosis formed the basis for what was reported in the Lancet," he wrote two years ago in a statement. "I played no part in the diagnostic process at all." ${ }^{34}$

Competing interests: The author has completed the ICJME unified disclosure form at www.icmje.org/coi_disclosure.pdf (available on request from the corresponding author) and declares no support from any organisation for the submitted work; no financial relationships at any time with any organisation that might have an interest in the submitted work; BD's investigation led to the GMC proceedings referred to in this report.

Provenance and peer review: Commissioned; externally peer reviewed.

1 Deer B. Tabulation of pathology proformas behind "new inflammatory bowel disease" claims. http://briandeer.com/solved/dhillon/tabulation.pdt.

2 Wakefield AJ, Murch SH, Anthony A, Linnell J, Casson DM, Malik M, et al. lleal lymphoid nodular hyperplasia, non-specific colitis and pervasive developmental disorder in children. Lancet 1998;351:637-41 [retracted].

3 General Medical Council. Determination on serious professional misconduct and sanction Andrew Jeremy Wakefield, 24 May 2010. www.gmc-uk.org/Wakefield_SPM_and SANCTION.pdf 32595267.pdf.

4 Deer B. How the case against the MMR vaccine was fixed. BMJ 2011;342:77-82.

5 Godlee F, Smith J, Marcovitch H. Wakefield's article linking MMR vaccine and autism was fraudulent. BMJ 2011;342:c7452.

6 Wakefield AJ, Anthony A, Murch SH, Thomson M, Montgomery SM, Davies S, et al Enterocolitis in children with developmental disorders. Am J Gastroenterol 2000;95:2285-95 [retracted].

7 Wakefield AJ. Developmental disorders in children and measles mumps rubella (MMR) vaccine. Interim report to the Legal Aid Board. 1999.

8 Dhillon A. Autistic enterocolitis: is it a histopathological entity? Histopathology 2007;50:794.

9 Fiocchi C. The normal intestinal mucosa: a state of 'controlled inflammation'. In: Targan SR, Shanahan F, Karp LC, eds. Inflammatory bowel disease: from bench to bedside. 2nd ed. Kluwer Academic, 2003.

10 Molavi DW. The practice of surgical pathology-a beginner's guide to the diagnostic process. Springer, 2008

11 Sayers and others v SmithKline Beecham and others. Writ filed October 91998.

12 Cedillo v Secretary for Health \& Human Services. Petition filed December 91998.

13 Deer B. Wakefield's "autistic enterocolitis" under the microscope. BMJ 2010;340:c1127.

14 General Medical Council $v$ Andrew Jeremy Wakefield, John Angus Walker-Smith and Simon Harry Murch. Commenced 16 July 2007. Concluded 24 May 2010.

15 Davies SE. Caution in assessing histopathological opinions [electronic response to Deer B. Wakefield's "autistic enterocolitis" under the microscope]. BMJ 2010. www.bmj.com/ content/340/bmj.c1127/reply\#bmj_el_235073?sid=8596e42f-0aa6-4380-afe6e6461772ba67.

16 Jenkins D, Balsitis M, Gallivan S, Dixon MF, Gilmour HM, Shepherd NA, et al. Guidelines for the initial biopsy diagnosis of suspected chronic idiopathic inflammatory bowel disease; the British Society of Gastroenterology initiative. J Clin Pathol 1997;50:93-105.

17 Tsang P, Rotterdam H. Biopsy diagnosis of colitis-possibilities and pitfalls. Am J Surg Pathol 1999;23:423-30. 


\section{MMR and bowel disease-how events unfurled}

1997-8: After broadly normal results from the Royal Free hospital pathology service, led by consultant histopathologist Susan Davies, intestinal biopsies from children later reported in Wakefield's 1998 Lancet paper are reassessed in the Royal Free medical school by consultant histopathologist Amar Dhillon. He uses grading sheets of his own design

1998: The Lancet publishes a 12 patient case series by Wakefield and 12 others from the Royal Free (including Davies, Dhillon) proposing a link between MMR and a "new syndrome" of bowel and brain damage involving enterocolitis and regressive autism. The paper claims that the data suggest that a connection between these is "real" and reflects "a unique disease process"

2003-4: After widespread media and public concern over these and other claims from Wakefield relating to autism, MMR vaccination rates in England fall, with only about $80 \%$ of 2 year olds having had the jab. In London, the figure is just $70 \%$

2008: Measles is declared endemic in England and Wales for the first time in 14 years

2010: A GMC fitness to practise panel strikes off Wakefield for, among other things, "irresponsible and dishonest" conduct over the research. The Lancet retracts the paper.

2011: Brian Deer's articles in the BMJ reveal evidence that Wakefield's claims to have found a temporal link between MMR and regressive autism was what the journal's editors called "an elaborate fraud"

2011: Wakefield hands documents supplied to him by the GMC, and which he says prove him innocent, to David L Lewis, a self-employed American environmental microbiologist. They contain Dhillon's histopathology reports and other reports compiled later by a trainee. Lewis forwards these to the $B M J$, arguing that they exonerate Wakefield

18 Carpenter HA, Talley NJ. The importance of clinicopathological correlation in the diagnosis of inflammatory conditions of the colon: histological patterns with clinical implications. $A m$ $J$ Gastroenterol 2000;95:878-96.

19 Mantzaris GJ. What is the natural history of a patient with non-specific colitis on large bowel histology? Ann Gastroenterol 2005;18:116-8.

20 Paski SC, Wightman R, Robert ME, Bernstein CN. The importance of recognizing cecal inflammation in health and avoiding the misdiagnosis of nonspecific colitis. $\mathrm{Am} \mathrm{J}$ Gastroenterol 2007;102:2294-9.

21 Levine DS, Haggitt RC. Normal histology of the colon. Am J Surg Path 1989;13:966-84

22 Montgomery EA. Biopsy interpretation of the gastrointestinal tract mucosa. Lippincott Williams \& Wilkins, 2006

23 Buie T, Campbell DB, Fuchs GJ, Furuta GT, Levy J, Vandewater J, et al. Evaluation, diagnosis, and treatment of gastrointestinal disorders in individuals with ASDs: a consensus report. Pediatrics 2010;125(suppl 1):S1-18.

24 Beattie RM, Walker-Smith JA, Murch SH. Indications for investigation of chronic gastrointestinal symptoms. Arch Dis Child 1995;73:354-5.

25 Wakefield AJ. Author's reply. Lancet 1998;351:908.

26 Williams CB, Nicholls S. Endoscopic features of chronic inflammatory bowel disease in childhood. Bailliere Clin Gastroenterol 1994:8:121-31.
27 Walker-Smith JA, Hamilton JR, Walker WA. Practical paediatric gastroenterology. Butterworths, 1983

28 Bartram $\mathrm{Cl}$, Halligan S. Radiological investigation of chronic inflammatory bowel disease in childhood. Bailliere Clin Gastroenterol 1994;8:101-19.

29 Eisenberg RL. Gastrointestinal pathology: a pattern approach. Lippincott Williams \& Wilkins 2003.

30 Murch S, Thomson M, Walker-Smith JA. Authors' reply. Lancet 1998;351:908.

31 Villanacci V, Bassotti G, Nascimbeni R, Cathomas G, Maurer CA, Fisogni S, et al. Colonic lymphoid aggregates in slow transit constipation. Dig Dis Sci 2007;52:321-3.

32 Mr Justice Bell. Judgment in Sayers \& Ors v Smithkline Beecham \& Ors. December 19 2001.

33 MacDonald TT, Domizio P. Autistic enterocolitis; is it a histopathological entity? Histopathology 2007:50:371-9.

34 Wakefield A. Complaint to the Press Complaints Commission. March 2009. (suspended on 10 February 2010 on grounds of non-pursuit by the complainant). http://briandeer.com/ solved/wakefield-complaint.pdf.

Cite this as: BMJ 2011;343:d6823

(c) BMJ Publishing Group Ltd 2011 


\section{Figure}

\begin{tabular}{|c|c|c|c|c|c|c|c|c|}
\hline & Duodenum & T Ileum & Caecum & $\begin{array}{l}\text { Ascending } \\
\text { colon }\end{array}$ & $\begin{array}{l}\text { Transverse } \\
\text { colon }\end{array}$ & $\begin{array}{l}\text { Descending } \\
\text { colon }\end{array}$ & $\begin{array}{l}\text { Sigmoid } \\
\text { colon }\end{array}$ & Rectum \\
\hline \multicolumn{9}{|c|}{ Child 1} \\
\hline A & & & 1 & & & 0 & 0 & 0 \\
\hline C & & & 1 & & & 0 & 0 & 0 \\
\hline D & & & 0 & & & 0 & 0 & 0 \\
\hline$R$ & & & 1 & & & 0 & 0 & 0 \\
\hline \multicolumn{9}{|c|}{ Child 2} \\
\hline A & & 0 & 0 & 0 & 0 & & 0 & 0 \\
\hline c & & 0 & 1 & 1 & 1 & & 1 & 1 \\
\hline D & & 0 & 0 & 0 & 0 & & 0 & 0 \\
\hline $\mathrm{R}$ & & 0 & 0 & 0 & 0 & & 0 & 0 \\
\hline \multicolumn{9}{|c|}{ Child 3} \\
\hline A & 0 & 0 & 0 & 0 & 0 & & 0 & 0 \\
\hline c & 1 & 0 & 1 & 1 & 1 & & 1 & 1 \\
\hline D & 0 & 0 & 0 & 0 & 0 & & 0 & 0 \\
\hline$R$ & 0 & 0 & 0 & 0 & 0 & & 0 & 0 \\
\hline \multicolumn{9}{|c|}{ Child 4} \\
\hline A & & 0 & 0 & 0 & 0 & 0 & 0 & 1 \\
\hline c & & 0 & 1 & 1 & 1 & 1 & 1 & 1 \\
\hline D & & 0 & 0 & 0 & 0 & 0 & 0 & 0 \\
\hline $\mathrm{R}$ & & 0 & 1 & 0 & 1 & 0 & 0 & 0 \\
\hline
\end{tabular}

\begin{tabular}{|c|c|c|c|c|c|c|c|}
\hline & & & & & & & \\
\hline$A$ & 0 & 0 & & 0 & 0 & 0 & 0 \\
\hline C & 0 & 1 & & 1 & 1 & 1 & 1 \\
\hline D & 0 & 0 & & 0 & 0 & 0 & 0 \\
\hline $\mathrm{R}$ & 0 & 1 & & 1 & 1 & 1 & 0 \\
\hline \multicolumn{8}{|c|}{ Child 6} \\
\hline A & 0 & 0 & & 1 & & 1 & 1 \\
\hline C & 0 & 1 & & 1 & & 1 & 2 \\
\hline D & 0 & 0 & & 0 & & 0 & 0 \\
\hline $\mathrm{R}$ & 0 & 0 & & 0 & & 0 & 1 \\
\hline \multicolumn{8}{|c|}{ Child 7} \\
\hline A & 0 & 0 & & 0 & 0 & 0 & 0 \\
\hline c & 0 & 0 & & 0 & 0 & 0 & 0 \\
\hline D & 0 & 0 & & 0 & 0 & 0 & 0 \\
\hline $\mathrm{R}$ & 0 & 0 & & 0 & 0 & 0 & 0 \\
\hline \multicolumn{8}{|c|}{ Child 8} \\
\hline$A$ & 0 & 0 & & 0 & & & 1 \\
\hline C & 0 & 1 & & 0 & & & 1 \\
\hline D & 0 & 0 & & 0 & & & 0 \\
\hline $\mathrm{R}$ & 0 & 0 & & 0 & & & 0 \\
\hline \multicolumn{8}{|c|}{ Child 9} \\
\hline A & 0 & 0 & 0 & 0 & 0 & 0 & 0 \\
\hline c & 0 & 1 & 3 & 2 & 2 & 2 & 1 \\
\hline D & 0 & 0 & 0 & 0 & 0 & 0 & 0 \\
\hline $\mathrm{R}$ & 0 & 0 & 1 & 1 & 1 & 1 & 0 \\
\hline
\end{tabular}

\begin{tabular}{|c|c|c|c|c|c|c|c|}
\hline \multicolumn{8}{|c|}{ Child 10} \\
\hline A & 0 & 0 & 0 & 0 & & 0 & 0 \\
\hline C & 1 & 1 & 1 & 1 & & 1 & 1 \\
\hline D & 0 & 0 & 0 & 0 & & 0 & 0 \\
\hline$R$ & 0 & 0 & 0 & 0 & & 0 & 0 \\
\hline \multicolumn{8}{|c|}{ Child 12} \\
\hline A & & & 0 & 0 & 0 & & 0 \\
\hline C & & & 0 & 1 & 1 & & 1 \\
\hline D & & & 0 & 0 & 0 & & 0 \\
\hline$R$ & & & 0 & 0 & 0 & & 0 \\
\hline
\end{tabular}

A= Acute inflammation (polymorphs): 1=occasional lamina propria polymorphs, 2=crypt abscesses, 3=frank pus $C=$ Chronic inflammation lymphocytes and plasma cell: $1=$ slight increase in lamina propria mononuclear cells,

2 =moderate increase, $3=$ marked increase with $>2$ of lymphoid aggregates/follicles/biopsy

$D=$ Destructive epithelial change: $1=$ superficial erosions, 2 =aphthoid ulcers, $3=$ frank ulceration

$\mathrm{R}=$ Reactive/neoplastic epithelial architectural change: $1=$ bifid glands, goblet cell depletion, $2=$ gland atrophy plus

disarray pyloric/Paneth cell metaplasia, 3=villous change, "dysplasia"

Blue shading=specimens with lymphoid follicles or aggregates

Tabulation of key data from Dhillon's grading sheets for 11 of 12 children in Lancet paper (further details are available at http://briandeer.com/solved/dhillon/tabulation.pdf) 